\title{
MORPHOMETRIC VARIATION IN INDIAN SAMPLES OF THE COMMON MYNA, ACRIDOTHERES TRISTIS (AVES: STURNIDAE) \\ by
}

\author{
ALLAN J. BAKER \\ Department of Ornithology, Royal Ontario Museum, and Department \\ of Zoology, University of Toronto, Toronto, Ontario, Canada \\ \& \\ ABDUL MOEED \\ Ecology Division, Department of Scientific and Industrial Research, \\ Lower Hutt, New Zealand
}

\begin{abstract}
Morphometric variation in 9 characters of 347 Common Mynas from 10 localities in India was analysed statistically. Both sexes have differentiated similarly among localities in all characters. Character variability within localities is not significantly correlated with that among localities. The patterns of geographic variation are not clinally ordered; contiguous localities often are not most similar morphometrically.

Size variation, as represented multivariately by principal factor $I$, is not related linearly to corresponding environmental variation among localities. However, relative appendage proportions, as defined by principal factor II, regresses significantly on an altitude factor for both males and females. The comparatively small proportion of the total morphometric variation among localities accounted for by environmental variation suggests that other factors are operative in determining body size. It is speculated that geographic variation in interspecific competition and food particle size may also act as selective pressures in the evolution of optimal body size at each locality.
\end{abstract}

\section{INTRODUCTION}

The Common Myna (Acridotheres tristis) is endemic to southeast Asia. It occurs ubiquitously throughout its range from Afghanistan through the Indian subcontinent and Burma to Indochina (Ali \& Ripley, 1972). In the last century populations were introduced successfully to widespread and ecologically diverse habitats in South Africa (Kent, 1927), Mauritius (Woods, 1974), Hawaii (Dunmire, 1961), New Zealand (Thomson, 1922), Australia (Hall, 1907), Fiji (Derrick, $1965)$ and many other islands in the Pacific, Indian and South Pacific Oceans (Austin, 1962). The introduced populations apparently were founded with birds from India (Benson, 1960; Amadon, 1962; but see Brooke, 1976).

Comparisons of samples of birds from India with those from various introduced populations are of interest to evolutionists because they afford rare opportunities to assess the amount and rate of change that has occurred within a known time period. Estimates of evolutionary rates and assessments of the relative importance of gene flow, mutation, selection, random genetic drift and the Founder effect in promoting differentiation bear directly on the synthetic theory of evolution. A central assumption here is that the cumulative effects of microevolutionary processes within and among species are sufficient to explain macroevolutionary changes at higher levels of organization (Sokal, 1978).

A fundamental problem with studies of ancestral-descendent populations is that the former are no longer extant, but this difficulty can be largely overcome by using contemporary populations as representative of the ancestral stock (see Johnston \& Selander, 1971, 1973; Baker, 1980). The assumption implicit in this approach is that no or relatively little change has occurred in the "generations" gap in the interim. For the estimation of evolutionary rates it is important to establish an "ancestral" baseline to which each of the introduced populations can be compared.

In a previous paper (Baker \& Moeed, 1979) we reported on the development of variation and covariation in the introduced New Zealand populations of $A$. tristis. This paper presents an analysis 
of morphometric variation in extant Indian populations as a basis for future comparative studies of ancestral and descendent populations.

\section{MATERIALS AND METHODS}

A total of 347 adult Common Mynas were collected in India in 1974, 1975 and 1979 (table I). As far as was possible, the sampling localities were chosen to give broad geographic coverage (fig. 1), and to include the major ecotones in India. In this way we hoped to sample much of the morphological variation now manifest within and among Indian populations. As in Baker \& Moeed (1979) we excluded immatures from locality samples because of obvious age variation in size. Adults were recognized by gonad size, complete skull ossification and various feather characteristics as listed in table 1 of Brooke (1976).

Immediately after collection the following nine characters were recorded from each specimen: (1) Bill length - measured along the dorsal surface of the culmen from the tip to the junction of the rhampotheca with the feathers. (2) Premaxilla length - measured from the anterior margin of the nasal aperture to the tip of the bill. (3) Bill width - measured laterally at the posterior margin of the nasal aperture. (4) Bill depth - measured perpendicularly from the junction of the feathers on the culmen to the ventral margin of the lower mandible. (5) Tarsus length - measured diagonal-

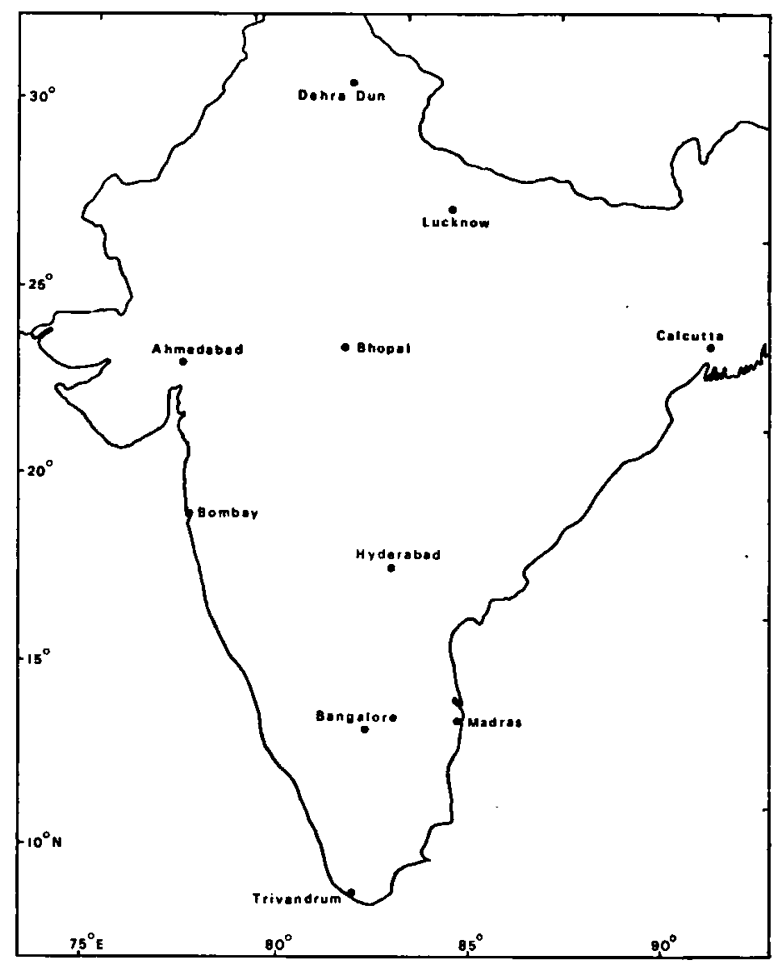

Fig. 1. Map of India showing localities where samples of Common Mynas were collected for this study.

ly from the posterior aspect of the joint between the tibiotarsus and the tarsometatarsus, to the distal border of the last undivided scute on the anterior of the tarsometatarsus. (6) Middle toe length measured anteriorly from the distal border of the last undivided scute on the tarsometatarsus to the base of the claw. (7) Wing length - measured as

TAB LE I

Samples of Common Mynas used in this study.

\begin{tabular}{|c|c|c|c|c|c|}
\hline \multirow[t]{2}{*}{ Locality } & \multirow[t]{2}{*}{ Acronym } & \multirow[t]{2}{*}{ Dates of collection } & & \multicolumn{2}{|c|}{ No. of specimens } \\
\hline & & & & Males & Females \\
\hline Dehra Dun & DEHR & 1-2 December, 1979 & & 16 & 18 \\
\hline Lucknow & LUCK & 17-18 November, 1979 & & 12 & 14 \\
\hline Ahmedabad & AHME & 14-15 November, 1979 & & 18 & 13 \\
\hline Bhopal & BHOP & 11-15 May, 1974; 8 November, 1975 & & 37 & 24 \\
\hline Calcutta & CALC & 31 October-2 November, 1975 & & 19 & 13 \\
\hline Bombay & BOMB & 24-26 October, 1975; 13 November, 1979 & & 24 & 19 \\
\hline Hyderabad & HYDE & 20 November, 1979 & & 11 & 14 \\
\hline Bangalore & BANG & 23-24 November, 1979 & & 16 & 13 \\
\hline Madras & MADR & 3 November, 1975 & & 14 & 13 \\
\hline \multirow[t]{2}{*}{ Trivandrum } & TRIV & 26-27 November, 1979 & & 20 & 19 \\
\hline & & & Total & 187 & 160 \\
\hline
\end{tabular}


the chord of the flattened wing, from the carpal flexure to the tip of the longest primary. (8) Tail length - measured from the point of emergence of the two central rectrices to the tip of the longest rectrix. (9) Body weight. Measurements of characters (1) - (6) were recorded with dial calipers to the nearest $0.1 \mathrm{~mm}$, characters (7) and (8) were measured with a rule accurate to $1 \mathrm{~mm}$, and weight was recorded on a balance to the nearest $1 \mathrm{~g}$.

Because Common Mynas are sexually dimorphic in size (Baker \& Moeed, 1979), we have analysed variation in the sexes separately beyond. Relative character variability within and among localities was assessed with residuals from regression of pooled within-locality and among-locality standard deviations on respective grand means of characters. The among-locality standard deviations were computed as the square root of the added variance component from analysis of variance of each character. Residuals were used in preference to the conventional coefficients of variation because the standard deviations were positively correlated with the grand means of characters. Dividing standard deviations by the grand means did not remove the effect of the latter as intended, but instead induced a negative correlation between the coefficients of variation and the grand means, i.e., characters with small grand means have large coefficients of variation, and vice-versa. This is clearly an undesirable property which can be avoided by using residuals from regression (Baker, 1980).

Patterns of character variation among localities were assessed univariately with single classification analysis of variance. If significant differences were found among means, maximally non-significant subsets were defined with the sums-of-squares simultaneous test procedure (SS-STP), an a posteriori multiple comparisons test (Gabriel \& Sokal, 1969). Subsets were based on ranked means as in Power (1970), rather than on geographic contiguity of samples.

Variation among localities was also investigated with multivariate statistical methods. Locality centroids were tested for differences in location using multivariate analysis of variance, and then the samples were subjected to generalized discriminant analysis (Cooley \& Lohnes, 1971; Seal, 1966).
Circular $95 \%$ confidence regions for each centroid were calculated as in Baker \& Moeed (1979).

The relationship between interlocality morphometric variation and environmental variables was examined with principal factor analysis (Harman, 1967) and stepwise multiple regression, as has been done previously by Atchley (1971), Baker et al. (1978) and Baker \& Moeed (1979). Correlation matrices were computed among standardized locality means separately for the morphometric and environmental variables. Principal factors with eigenvalues greater than unity were extracted from each matrix. The environmental factors were rotated to simple structure using the Varimax criterion (Kaiser, 1958) to increase their interpretability. Factor scores for each locality were calculated by projecting locality means onto respective factors. Stepwise multiple regressions were then performed with the environmental factors as "independent" variables and the morphometric factors as the "dependent" variable.

Environmental data for each sample locality were obtained from the India Meteorological Department publication "Climatological tables of observations in India (1931-1960)". As in our previous study (Baker \& Moeed, 1979) we selected 12 environmental variables to describe interlocality climatic differences: (1) mean annual precipitation, (2) mean January (winter) and (3) mean May (summer) temperatures, (4) mean maximum January and (5) May temperatures, (6) mean minimum January and (7) May temperatures, (8) latitude, (9) longitude, (10) altitude, (11) isophane and (12) relative humidity. Data were taken from meteorological stations closest to collecting sites, as follows: Ahmedabad (Civil Airport), Bangalore (Hindustan Airport), Bhopal (Bairagarh Airport), Bombay (Colaba), Calcutta (Alipore), Dehra Dun (Survey of India), Hyderabad (Begampet Airport), Lucknow (Aamausi), Madras (Minambukkam) and Trivandrum (Trivandrum Observatory).

\section{RESULTS}

\section{Character variability}

Character variability within and among localities along with grand means of characters are given in 
TABLE II

Grand means $(Y)$, within-locality character variability $\left(R_{W}\right)$ and among-locality character variability $\left(R_{A}\right)$. Consult methods section for methods of calculating $R_{W}$ and $R_{A}$.

\begin{tabular}{lrccrcrc}
\hline & \multicolumn{3}{c}{ Males } & & \multicolumn{3}{c}{ Females } \\
\cline { 2 - 5 } \cline { 3 - 7 } Character & \multicolumn{1}{c}{$\boldsymbol{Y}$} & $R_{W}$ & $R_{\boldsymbol{A}}$ & & $Y$ & $R_{W}$ & $R_{A}$ \\
\hline Bill length & 22.4 & -0.001 & +0.069 & & 21.7 & -0.009 & +0.104 \\
Premaxilla length & 15.9 & -0.018 & +0.142 & & 15.9 & -0.003 & +0.103 \\
Bill width & 7.2 & +0.110 & -0.102 & & 6.9 & +0.188 & -0.140 \\
Bill depth & 8.1 & +0.174 & +0.009 & & 7.6 & +0.217 & -0.045 \\
Wing length & 145.9 & +0.428 & -0.100 & & 140.6 & +0.278 & -0.046 \\
Tail length & 87.9 & -0.764 & -0.035 & & 83.8 & -0.382 & -0.084 \\
Tarsus length & 36.7 & -0.079 & +0.034 & & 38.4 & -0.140 & +0.100 \\
Middle toe length & 30.4 & -0.170 & -0.021 & & 29.2 & -0.149 & +0.008 \\
\hline
\end{tabular}

table II. Weight was excluded from the analysis because it is recorded in different units to the other characters and thus cannot be referred to a common scale. Within localities the most variable character is wing length, and the least variable is the other feather character, tail length. Bill depth and width are more variable than are the bill length characters, and middle toe length and tarsus length show relatively low variability. This pattern of character variability is similar for the sexes, their within-locality residuals being strongly correlated $(r=0.940, P<0.001)$.
Character variation among localities differs from that expressed within localities. Bill length, premaxilla length and tarsus length vary most among localities. Bill width, wing length, and tail length are relatively less variable geographically, and bill depth and middle toe length are intermediate in variability between these two suites of characters. Characters vary similarly among localities in the sexes; the respective $R_{A}$ values for males and females are significantly correlated $(r=$ $0.848, P<0.01$ ).

In neither males nor females is there a signifi-

TABLE III

Means \pm standard errors of 9 characters of 10 samples of Common Mynas.

\begin{tabular}{|c|c|c|c|c|c|c|c|c|c|}
\hline \multicolumn{10}{|c|}{ Characters } \\
\hline Locality & $\begin{array}{l}\text { Bill } \\
\text { length }\end{array}$ & $\begin{array}{l}\text { Premaxilla } \\
\text { length }\end{array}$ & $\begin{array}{l}\text { Bill } \\
\text { width }\end{array}$ & $\begin{array}{l}\text { Bill } \\
\text { depth }\end{array}$ & $\begin{array}{l}\text { Wing } \\
\text { length }\end{array}$ & $\begin{array}{l}\text { Tail } \\
\text { length }\end{array}$ & Weight & $\begin{array}{l}\text { Tarsus } \\
\text { length }\end{array}$ & $\begin{array}{l}\text { Middle toe } \\
\text { length }\end{array}$ \\
\hline \multicolumn{10}{|c|}{ MALES } \\
\hline Dehra Dun & $22.3 \pm 0.20$ & $15.8 \pm 0.21$ & $6.8 \pm 0.08$ & $7.8 \pm 0.08$ & $149 \pm 0.8$ & $88 \pm 0.6$ & $117 \pm 1.6$ & $39.0 \pm 0.34$ & $29.9 \pm 0.28$ \\
\hline Lucknow & $22.0 \pm 0.23$ & $15.7 \pm 0.19$ & $7.0 \pm 0.12$ & $8.0 \pm 0.08$ & $146 \pm 1.2$ & $89 \pm 1.4$ & $124 \pm 4.3$ & $40.8 \pm 0.33$ & $30.8 \pm 0.35$ \\
\hline Ahmedabad & $21.9 \pm 0.16$ & $15.4 \pm 0.17$ & $7.1 \pm 0.10$ & $8.0 \pm 0.08$ & $146 \pm 1.0$ & $90 \pm 0.8$ & $118 \pm 2.0$ & $39.5 \pm 0.28$ & $30.5 \pm 0.16$ \\
\hline Bhopal & $22.2 \pm 0.18$ & $16.2 \pm 0.16$ & $7.4 \pm 0.05$ & $8.3 \pm 0.06$ & $141 \pm 0.6$ & $84 \pm 0.6$ & $115 \pm 1.4$ & $38.8 \pm 0.21$ & $28.8 \pm 0.23$ \\
\hline Calcutta & $22.4 \pm 0.23$ & $16.3 \pm 0.21$ & $7.6 \pm 0.10$ & $8.2 \pm 0.10$ & $141 \pm 1.0$ & $85 \pm 0.6$ & $112 \pm 1.7$ & $39.6 \pm 0.34$ & $29.9 \pm 0.35$ \\
\hline Bombay & $22.2 \pm 0.23$ & $16.0 \pm 0.19$ & $7.7 \pm 0.12$ & $8.3 \pm 0.08$ & $146 \pm 0.7$ & $89 \pm 0.8$ & $130 \pm 2.0$ & $40.4 \pm 0.29$ & $30.6 \pm 0.26$ \\
\hline Hyderabad & $21.9 \pm 0.30$ & $15.2 \pm 0.22$ & $6.7 \pm 0.11$ & $7.7 \pm 0.12$ & $146 \pm 1.2$ & $89 \pm 0.6$ & $116 \pm 2.5$ & $38.1 \pm 0.42$ & $30.0 \pm 0.35$ \\
\hline Bangalore & $23.4 \pm 0.17$ & $16.6 \pm 0.21$ & $7.0 \pm 0.09$ & $8.1 \pm 0.10$ & $152 \pm 0.8$ & $93 \pm 1.0$ & $133 \pm 2.8$ & $40.8 \pm 0.30$ & $31.5 \pm 0.23$ \\
\hline Madras & $23.8 \pm 0.28$ & $16.5 \pm 0.18$ & $7.6 \pm 0.14$ & $8.5 \pm 0.12$ & $146 \pm 1.1$ & $85 \pm 1.0$ & $139 \pm 3.8$ & $40.7 \pm 0.36$ & $31.1 \pm 0.34$ \\
\hline Trivandrum & $22.1 \pm 0.24$ & $15.6 \pm 0.13$ & $6.7 \pm 0.08$ & $7.7 \pm 0.06$ & $146 \pm 0.9$ & $87 \pm 0.9$ & $118 \pm 2.5$ & $39.2 \pm 0.35$ & $30.8 \pm 0.24$ \\
\hline \multicolumn{10}{|c|}{ FEMALES } \\
\hline Dehra Dun & $21.3 \pm 0.19$ & $15.2 \pm 0.16$ & $6.6 \pm 0.09$ & $7.5 \pm 0.06$ & $144 \pm 0.8$ & $86 \pm 0.7$ & $105 \pm 1.5$ & $37.7 \pm 0.26$ & $29.3 \pm 0.24$ \\
\hline Lucknow & $21.7 \pm 0.28$ & $15.6 \pm 0.17$ & $6.8 \pm 0.09$ & $7.6 \pm 0.10$ & $139 \pm 1.0$ & $84 \pm 0.8$ & $112 \pm 2.7$ & $39.4 \pm 0.60$ & $30.0 \pm 0.51$ \\
\hline Ahmedabad & $21.0 \pm 0.19$ & $14.9 \pm 0.12$ & $6.7 \pm 0.10$ & $7.6 \pm 0.11$ & $139 \pm 0.9$ & $85 \pm 0.7$ & $104 \pm 1.9$ & $38.0 \pm 0.41$ & $29.1 \pm 0.33$ \\
\hline Bhopal & $21.6 \pm 0.23$ & $15.7 \pm 0.25$ & $7.3 \pm 0.07$ & $7.9 \pm 0.08$ & $137 \pm 0.7$ & $81 \pm 0.7$ & $106 \pm 1.2$ & $37.9 \pm 0.28$ & $27.6 \pm 0.23$ \\
\hline Calcutta & $22.0 \pm 0.30$ & $15.8 \pm 0.26$ & $7.5 \pm 0.11$ & $7.8 \pm 0.13$ & $138 \pm 1.5$ & $83 \pm 0.7$ & $111 \pm 1.7$ & $38.7 \pm 0.50$ & $29.2 \pm 0.31$ \\
\hline Bombay & $21.5 \pm 0.24$ & $15.5 \pm 0.18$ & $7.2 \pm 0.11$ & $7.8 \pm 0.09$ & $140 \pm 0.5$ & $85 \pm 0.5$ & $116 \pm 2.1$ & $38.4 \pm 0.42$ & $28.2 \pm 0.38$ \\
\hline Hyderabad & $21.0 \pm 0.17$ & $14.8 \pm 0.18$ & $6.5 \pm 0.11$ & $7.2 \pm 0.09$ & $138 \pm 1.2$ & $83 \pm 0.7$ & $104 \pm 1.6$ & $37.6 \pm 0.40$ & $29.1 \pm 0.30$ \\
\hline Bangalore & $22.6 \pm 0.23$ & $16.0 \pm 0.18$ & $6.7 \pm 0.08$ & $7.7 \pm 0.11$ & $146 \pm 0.8$ & $88 \pm 0.8$ & $126 \pm 2.3$ & $40.3 \pm 0.30$ & $30.8 \pm 0.31$ \\
\hline Madras & $22.8 \pm 0.31$ & $16.0 \pm 0.22$ & $7.4 \pm 0.14$ & $8.2 \pm 0.15$ & $141 \pm 0.8$ & $81 \pm 0.7$ & $127 \pm 3.0$ & $38.9 \pm 0.34$ & $29.5 \pm 0.34$ \\
\hline Trivandrum & $21.6 \pm 0.24$ & $14.9 \pm 0.20$ & $6.5 \pm 0.08$ & $7.2 \pm 0.05$ & $139 \pm 0.7$ & $82 \pm 0.7$ & $102 \pm 2.0$ & $37.4 \pm 0.24$ & $29.4 \pm 0.24$ \\
\hline
\end{tabular}




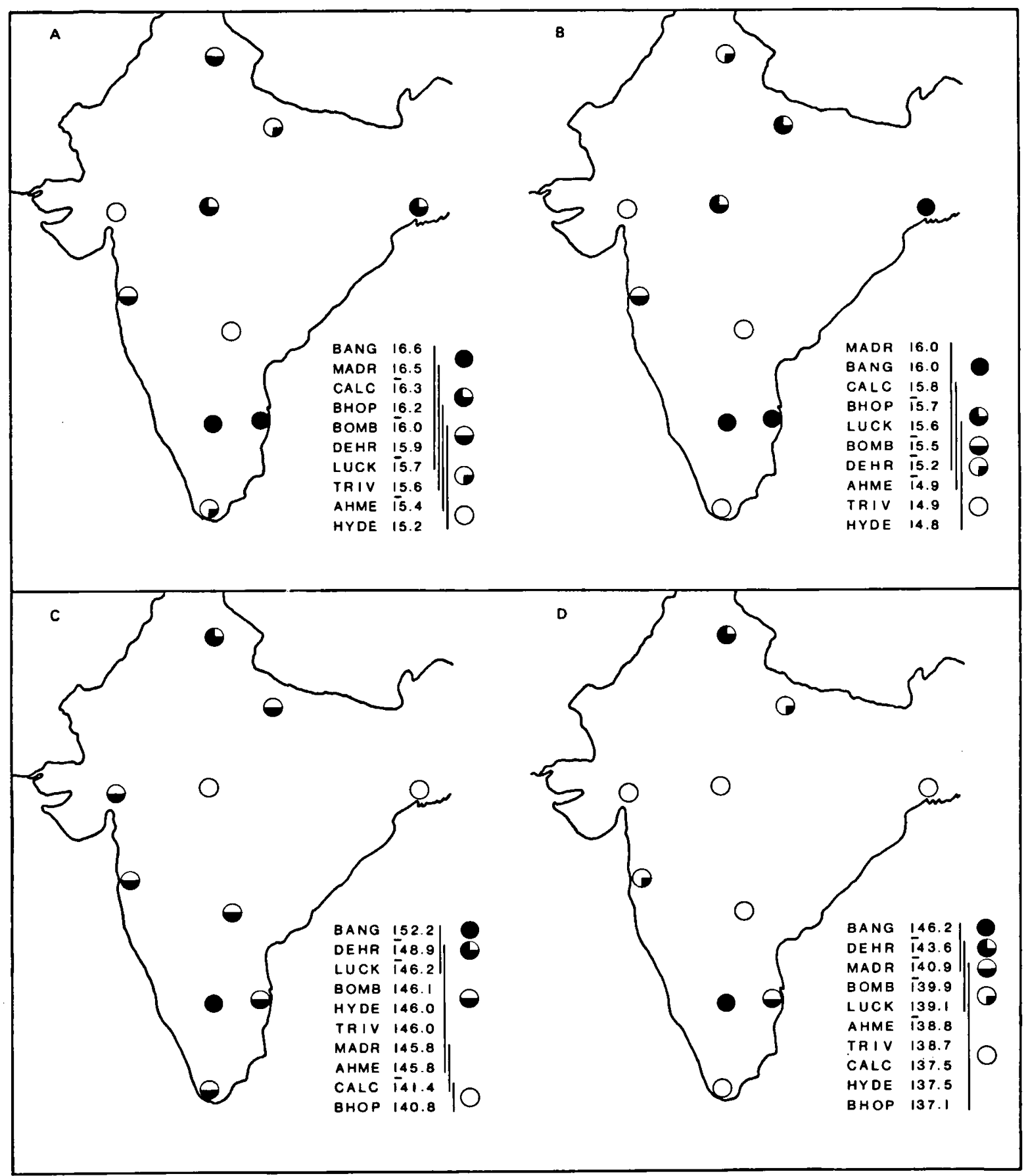

Fig. 2. Results of SS-STP for two exemplary morphometric characters of Common Mynas from 10 localities in India: A, premaxilla length of males; $B$, premaxilla length of females; $C$, wing length of males; $D$, wing length of females. Vertical lines define maximally nonsignificant subsets of locality means. Variously shaded circles indicate trends in character variation. The character range is divided into five equal parts from largest represented by solid circles through to smallest denoted by open circles. 
cant correlation between character variation within and among localities. For males $r=0.138(P=$ $0.745)$ and for females $r=0.227(P=0.589)$. Thus there is no significant tendency for Indian Common Mynas to vary most among localities in those characters that are most variable within localities (the so-called Kluge-Kerfoot effect - see Kluge \& Kerfoot (1973) and Sokal (1976)).

\section{Sample comparisons}

Univariate analysis of variance revealed statistically significant $(P<0.05)$ differences among locality means in all nine characters of both sexes. Patterns of geographic variation in each character are similar for males and females. The patterns are complex in that geographically contiguous localities often do not group in the same non-significant subset, and thus interlocality variation cannot be predicted reliably from geographic position alone. A feature of the SS-STP tests is that the south India samples from Bangalore and Madras have large character means. In females, four of the largest means (bill length, premaxilla length, bill depth and weight) are from the Madras sample, and four (wing length, tail length, tarsus length and middle toe length) are from Bangalore. In males, three of the largest means (bill length, bill depth and weight) are from the Madras sample, and five (premaxilla length, wing length, tail length, tarsus length and middle toe length) are from Bangalore (see table III).

The neighbouring samples from Trivandrum to the south and Hyderabad to the north contain much smaller birds. This abrupt morphometric transition is most pronounced in bill dimensions. The Trivandrum and Hyderabad samples have the smallest means for bill width and depth for both sexes, as does premaxilla length of females. Samples of birds from the Indo-gangetic Plain and northern Deccan Plateau (Dehra Dun, Lucknow, Bhopal, Calcutta and Ahmedabad) and coastal Bombay are intermediate in size in most characters. These trends are illustrated for two exemplary characters in fig. 2.

Although the univariate analyses are instructive in providing details of character variation, they lack the overview provided by analyses that consider joint variation in characters simultaneously.
We therefore supplemented the single character analyses of variance with multivariate statistical techniques. Multivariate analysis of variance indicated significant differences in the locations of locality centroids. For males, the $F$-transformation of Wilks' lambda $=6.508(D F=81$ and 1101, $P<0.001)$, and for females $F=6.198(D F=$ 81 and $927, P<0.001)$. It was therefore appropriate to proceed with generalized discriminant analysis.

For males, the first five discriminant functions were statistically significant $(P<0.05)$, collectively accounting for $96.06 \%$ of the variation among localities. For females, the first six discriminant functions were significant, explaining $97.76 \%$ of among locality variation. As the major portion of this variation was expressed on the first three discriminant functions $(88.15 \%$ in males and $85.23 \%$ in females), they were used to depict morphometric differentiation of the samples. Twodimensional plots of the sample centroids are shown in figs. 3 and 4.

In both sexes the centroids of the Bangalore and Madras samples are clearly distinct from the rest. The Calcutta and Bhopal centroids group together, and the extreme southern Trivandrum and the remaining Indo-gangetic Plain centroids form a series with overlapping confidence circles. The Bombay centroid is located between these latter two groups.

Discriminant function I of males separates the Bhopal, Calcutta and Bangalore centroids from the remainder on differences in bill dimensions (except bill length), leg dimensions and feather characters. Discriminant function I of females is qualitatively different from that of males, serving principally to distinguish the Madras centroid from those of Trivandrum and the Indo-gangetic Plain samples. The same bill dimension character suite as in males contributes to this discrimination, but among-sample differences in middle toe length and wing length are important too. In males separation of the Madras centroid from the rest is achieved mainly on differences in bill length and body weight, as expressed by discriminant function II. This result is consistent with the large means for these characters in the Madras sample (table III). Discriminant function II of females distin- 

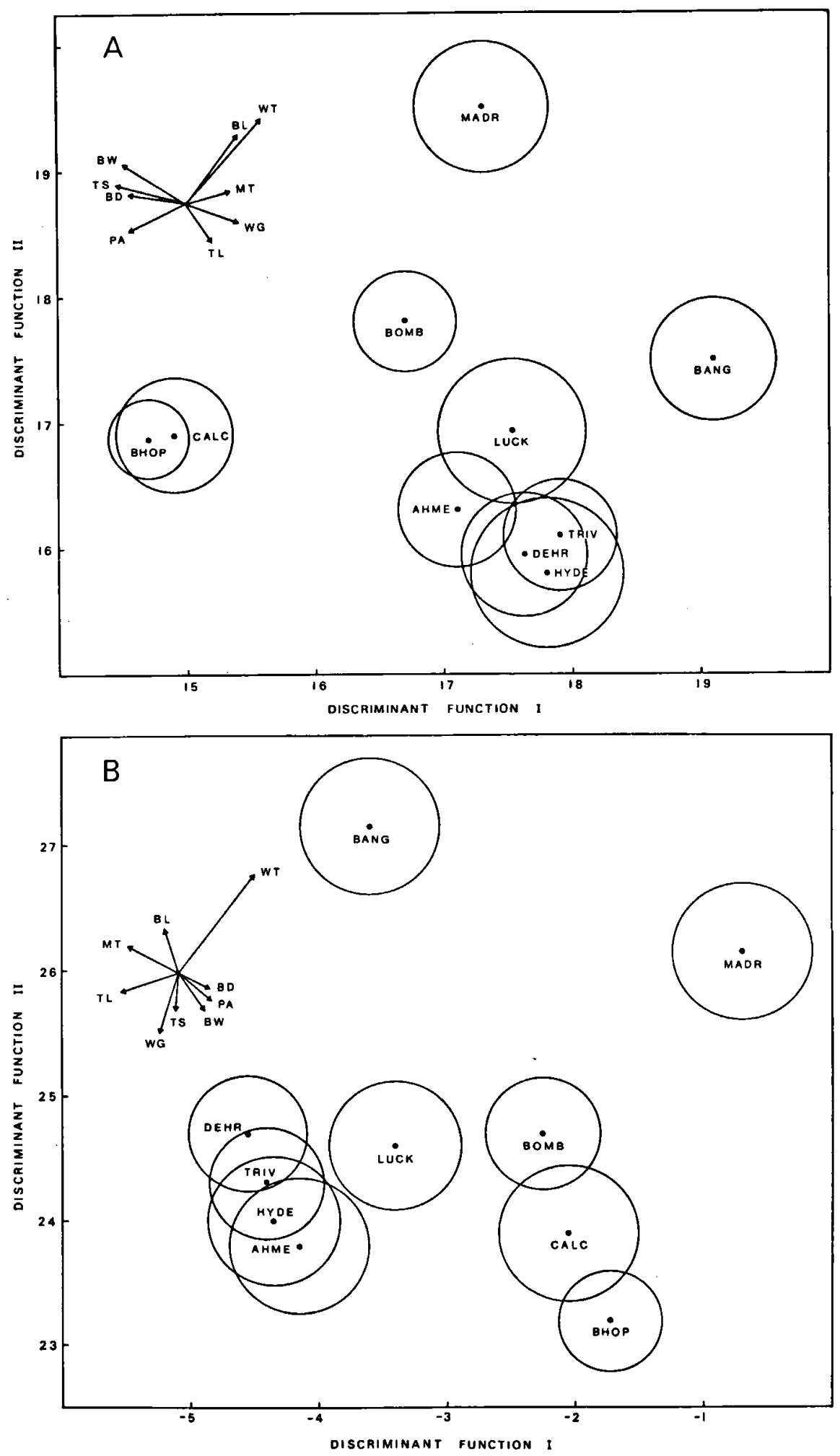

Fig. 3. Bivariate plots of discriminant function I against discriminant function II for (A) males and (B) females of Common Mynas from 10 Indian localities. Acronyms identify localities as in table 1. Locality centroids are enclosed by $95 \%$ "confi-. dence circles." Contributions of individual characters to the separation of locality centroids are indicated by the magnitude and direction of the character vectors, which are scaled relative to the pooled within-group standard deviations. 

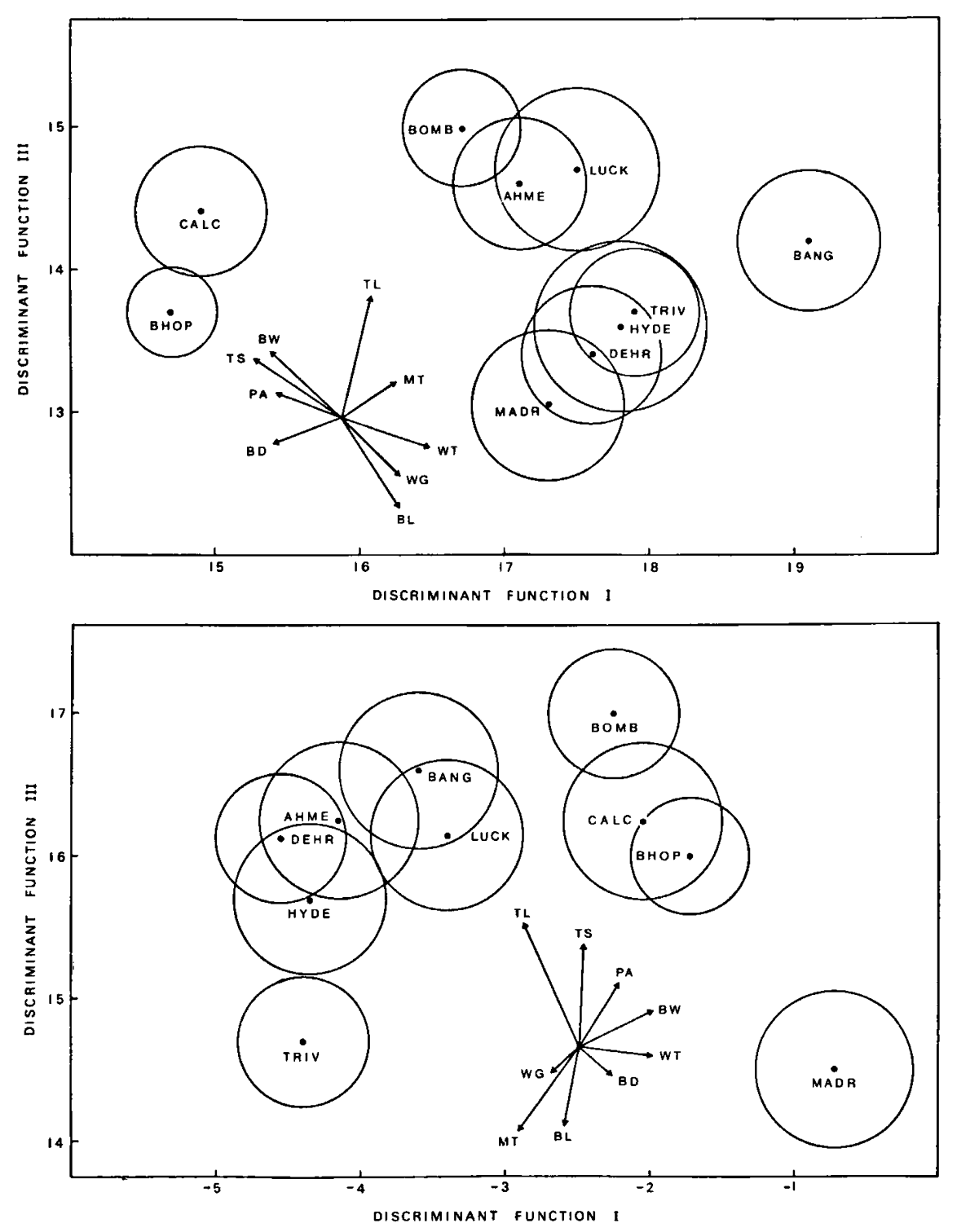

Fig. 4. Bivariate plots of discriminant function I against III for males (top) and females (bottom) of Common Mynas from 10 Indian localities. For further explanation see caption to fig. 3.

guishes the Bangalore and Madras centroids from the others, but on differences in weight as well as lengths of the bill, wing and tarsus.

Discriminant function III of males and females is effective in distinguishing the Bombay and Madras centroids (and in males the Trivandrum centroid) from each other, though characters contribute differently for the sexes. In males the most important discriminating characters are the lengths of the bill, premaxilla, tail, tarsus and middle toe, whereas in females only the lengths of the bill and tail are important. Overall, the dispersion of the sample centroids in discriminant space is quite similar for the sexes, indicating that they have undergone similar patterns of geographic variation.

Association of climatic and morphometric variation The morphometric characters are all strongly intercorrelated so it is desirable to reduce them to a smaller set of uncorrelated principal factors which 


\section{TABLE IV}

The first two principal factors of a matrix of correlations among means of 9 morphometric characters from 10 Indian samples of Common Mynas.

\begin{tabular}{|c|c|c|c|c|}
\hline \multirow[b]{2}{*}{ Character } & \multirow[b]{2}{*}{ Sex } & \multicolumn{2}{|c|}{ Factor } & \multirow[t]{2}{*}{ Communality } \\
\hline & & I & II & \\
\hline \multirow[t]{2}{*}{ Bill length } & Male & 0.867 & -0.026 & 0.752 \\
\hline & Female & 0.918 & -0.084 & 0.849 \\
\hline \multirow{2}{*}{ Premaxilla length } & Male & 0.798 & -0.371 & 0.774 \\
\hline & Female & 0.930 & -0.273 & 0.939 \\
\hline \multirow[t]{2}{*}{ Bill width } & Male & 0.548 & -0.740 & 0.848 \\
\hline & Female & 0.515 & -0.810 & 0.921 \\
\hline \multirow[t]{2}{*}{ Bill depth } & Male & 0.725 & -0.642 & 0.938 \\
\hline & Female & 0.747 & -0.569 & 0.882 \\
\hline \multirow[t]{2}{*}{ Wing length } & Male & 0.354 & 0.878 & 0.896 \\
\hline & Female & 0.540 & 0.704 & 0.787 \\
\hline \multirow{2}{*}{ Tail length } & Male & 0.155 & 0.869 & 0.779 \\
\hline & Female & 0.277 & 0.809 & 0.731 \\
\hline \multirow[t]{2}{*}{ Weight } & Male & 0.907 & 0.227 & 0.874 \\
\hline & Female & 0.952 & 0.029 & 0.907 \\
\hline \multirow[t]{2}{*}{ Tarsus length } & Male & 0.880 & 0.133 & 0.792 \\
\hline & Female & 0.881 & 0.272 & 0.850 \\
\hline \multirow[t]{2}{*}{ Middle toe length } & Male & 0.652 & 0.647 & 0.844 \\
\hline & Female & 0.457 & 0.750 & 0.771 \\
\hline
\end{tabular}

are linear combinations of the original characters. For both sexes two factors with eigenvalues greater than unity were extracted from the correlation matrices based on locality character means (table IV). Collectively, the two factors account for $83.32 \%$ and $84.60 \%$ of the character variances of males and females respectively. Thus the factors summarize the major orthogonal components of variation among localities.

Principal factor $I$ is very similar for the sexes as all characters correlate positively with it. All characters except wing and tail length load highly on factor $I$, and thus it can be generalized as representing size and size-related shape changes (Jolicoeur \& Mosimann, 1960; Gibson et al., 1976). Factor II has high negative loadings for bill width and depth, and high positive loadings for wing length, tail length and middle toe length. These inversely covariant character suites indicate that slender-billed birds have relatively long wings and tails (as in the Dehra Dun and Trivandrum samples) and vice-versa (as in the Bhopal and Calcutta samples).

The congruence in pattern of the factor loadings for the sexes was assessed using Bryant's (1977) measure of commonality, computed as the correlation of loadings within respective factors of males and females and then averaged across factors (the factors are weighted by their respective eigenvalues). The factor solutions are very similar for males and females, their communality value being 0.934 (where 1.0 equals identity of solutions).

Principal factor analysis of the environmental data resolved climatic variation among localities into three uncorrelated factors with eigenvalues

\section{TABLE V}

Varimax rotated factor matrix of 12 environmental variables for 10 selected weather stations in India.

\begin{tabular}{lrrrr}
\hline Environmental variable & \multicolumn{3}{c}{ Factor } & Communality \\
\cline { 2 - 4 } & \multicolumn{1}{c}{ I } & II & III \\
\hline Mean annual precipitation & -0.104 & -0.037 & 0.873 & 0.774 \\
Mean January temperature & 0.978 & 0.083 & 0.078 & 0.970 \\
Mean May temperature & -0.230 & 0.926 & -0.208 & 0.954 \\
Mean maximum January temperature & 0.933 & 0.111 & -0.229 & 0.935 \\
Mean maximum May temperature & -0.557 & 0.436 & -0.689 & 0.975 \\
Mean minimum January temperature & 0.975 & 0.083 & 0.145 & 0.979 \\
Mean minimum May temperature & 0.278 & 0.915 & -0.223 & 0.964 \\
Latitude & -0.957 & 0.186 & 0.054 & 0.953 \\
Longitude & -0.159 & 0.356 & 0.353 & 0.276 \\
Altitude & -0.337 & -0.816 & -0.227 & 0.831 \\
Isophane & -0.957 & -0.187 & -0.071 & 0.958 \\
Relative humidity & 0.684 & -0.108 & 0.645 & 0.895 \\
Eigenvalue & 5.82 & 3.00 & 1.64 & \\
\% variance explained & 48.53 & 25.04 & 13.63 & \\
\hline
\end{tabular}


greater than 1.0. Varimax rotation to simple structure produced interpretable factors. The three rotated factors accounted for $87.20 \%$ of the environmental variance, with $48.53 \%$ explained on I, $25.04 \%$ on II and $13.63 \%$ on III (table V).

Climate factor I represents variation among localities in winter temperatures which are negatively correlated with latitude and isophane, i.e., winter temperatures are cooler in northern localities. Factor II reflects an inverse relationship between altitude and summer temperatures, elevated localities such as Bangalore and Dehra Dun having lower summer temperatures. Factor III is a precipitation factor dominated by high positive loadings from mean annual precipitation and relative humidity. The negative loading of May temperatures occurs because high rainfall localities such as Trivandrum and Dehra Dun have more equable May temperatures than do lower rainfall localities like Ahmedabad, Bhopal and Hyderabad.

Stepwise multiple regressions of each morphometric factor on the environmental factors produced similar results for the sexes (table VI). None of the environmental factors entered significantly in regression with "size" factor I. Only the "appendage proportions" factor II regressed significantly on "altitude" factor II. The altitude factor accounts for $57.8 \%$ of the variation of the morphometric factor II of males and $38.1 \%$ of that of females. It is thus possible to attribute only a small portion of the morphometric variation among localities to environmental variation. Only $23.99 \%$ of the total morphometric factor variance of males and $14.26 \%$ of females is thereby explained.

The association of appendage proportions and

\section{TABLE VI}

Significant multiple regressions of Varimax rotated climatic factors onto principal axis morphometric factors of 10 Indian samples of Common Mynas.

\begin{tabular}{llll}
\hline Morphometric factor & $\begin{array}{l}\text { Regression } \\
\text { Coefficients }\end{array}$ & $r^{2}$ & F-ratio \\
\hline $\begin{array}{l}\text { Males } \\
\text { II }\end{array}$ & -0.873 (II) & 0.578 & 10.938 \\
$\begin{array}{l}\text { Females } \\
\text { II }\end{array}$ & -0.741 (II) & 0.381 & 4.932 \\
\hline
\end{tabular}

the altitude factor of climate suggests that wetbulb temperatures might be related to wing length (and thus general size) as has been shown for some North American species of passerines (James, 1970). Wet-bulb temperatures incorporate temperature and evaporation components which may be more relevant in ecogeographic adaptation than are the two components treated separately. However, none of the multivariate morphometric factors (including size factor I) or wing length regress significantly on annual, January or May wetbulb temperatures.

\section{DISCUSSION}

The statistical analyses of morphometric variation in the Indian samples of $A$. tristis demonstrate clearly that both sexes have differentiated significantly among localities in all characters. Individual characters differ considerably in their variability. Bill length, premaxilla length and tarsus length are the most variable geographically, whereas bill width, wing length and tail length are least variable within localities. In contradistinction, the most variable characters within localities are wing length, bill width and bill depth, but bill length and leg length measures show lower variability. Thus there is no statistically recognizable KlugeKerfoot effect; character variability within localities is not significantly correlated with that among localities.

The univariate and multivariate tests indicate that both sexes have developed similar geographic patterns of character variation. These patterns are complex in that samples from contiguous localities are often not most similar morphologically. It is therefore clear that variation in Common Mynas is not clinally ordered in the Indian subcontinent. The most striking morphometric transition is provided by the southern samples from Bangalore and Madras, which differ markedly from the neighbouring Trivandrum and Hyderabad samples to their south and north respectively.

Principal factor analysis of correlation matrices generated from locality character means produced very similar factor solutions for males and females. Factor I, summarizing size and size-related 
shape changes among localities, was not significantly related linearly with any of the environmental factors used in this study. Only factor II, representing relative proportions of body appendages, regressed significantly on the altitude environmental factor. A comparatively small proportion of the morphometric variation among localities can be accounted for by corresponding environmental variation; in males $24 \%$ and in females $14 \%$ is thereby explained.

The association of appendage proportions and the altitude factor is of general relevance to the current controversy on body size variation in homeotherms. In a study of geographic variation in 12 North American species of birds, James (1970) found a close relationship between wing length (and hence presumably body size) and wet-bulb temperature, consistent with the results of earlier studies on other species of birds by Hamilton (1958, 1961) and Power (1969). This led James (1970) to reformulate Bergmann's Rule as 'Intraspecific variation in homeotherms is related to a combination of climatic variables that includes temperature and moisture. Small size is associated with hot humid conditions, larger size with cooler or drier conditions". The tendency for birds to have longer wings at higher altitude localities (see, for example, Snow (1954) and Moreau (1957)) is predicted by James' reformulation because elevated localities are cooler or drier than their lower counterparts.

Variation in size in Common Mynas in India conforms only approximately with this generalization. Large birds are found at elevated localities with cooler, less humid climates (Bangalore and Dehra Dun), but so are small birds (Hyderabad). Small birds are found at low altitude localities with hot humid climates (Trivandrum, Calcutta) and so are large birds (Bombay). Thus neither multivariate morphometric factors or wing length alone regress significantly on wet-bulb temperatures.

Other hypotheses have been advanced to explain geographic variation in body size in homeotherms. McNab (1971) concluded that body size in geographically variable mammalian carnivores and granivores is determined by latitudinal gradients in food particle size availability and interspecific competition (but see Rosenzweig, 1968). The size of trophic structures and food particle size have been shown to be correlated in some species (Hespenheide, 1966, 1973; Pulliam \& Enders, 1971; Willson, 1971; Willson \& Harmeson, 1973). Interspecific competition for food therefore can be reduced by maximizing size differences among coexisting species at localities (MacArthur, 1958, 1972; Schoener, 1965, 1970; Cody, 1973; Hespenheide, 1973; Abbott et al., 1977).

Common Mynas often occur in large feeding flocks in intensively cultivated regions of India. These flocks commonly include or overlap with similar aggregations of one or more species of birds, particularly Starlings (Sturnus vulgaris), Pied Mynas (S. contra), Rosy Pastors (S. roseus), Bank Mynas (Acridotheres ginginianus), Jungle Mynas (A. fuscus) and House Crows (Corvus splendens). These species compete for common food resources (principally insects - see Sengupta, 1976 and Watling, 1975) along a variable geographic gradient because of their differential distributions and abundance in India (see Ali \& Ripley, 1972). Hence at least part of the body size variation in Indian Common Mynas could derive from geographic variation in interspecific competition and food particle size.

We want to emphasize the point made by Mosimann \& James (1979) that the hypotheses seeking to explain geographic trends in body size variation by either climatic adaptation or interspecific competitive processes are not necessarily mutually exclusive. It seems likely that both of these factors operate as selective pressures for the evolution of optimal body size at a locality, and the task for the future is to unravel their relative contributions.

\section{ACKNOWLEDGEMENTS}

We gratefully acknowledge the following people for their generous assistance and hospitality which ensured the success of our field work in India: Humayun Adulali, Iftakhar Ahmed, Jamal Iftakhar, Sher Ali, Dr. B. Biswas, S. Chattopadhyay, J. C. Daniel, Zafar Futehally, Professor Madhav Gadgil, Dr. Robert B. Grubh, Virendra Kumar, Dr. B. S. Lamba, Mohammed Mubeen, Dr. A. K. Mukherjee, S. M. Mushfique, Dr. S. C. Nair, Rex Pimento, Professor M. R. N. Prasad, Dr. S. R. V. Rao, Tariq Raza, S. S. Saha and Romulus Whittaker. The manuscript benefited from the constructive criticisms of Dr. J. C. Barlow and Dr. A. R. Gibson. We 
thank Pat Urquhart for providing excellent secretarial assistance in all phases of this study. Financial support for this study was provided by the Natural Science and Engineering Research Council of Canada (grant A0200 to A.J.B.) and the Royal Ontario Museum.

\section{REFERENCES}

Aвbott, I., L. K. Aвbott \& P. R. Grant, 1977. Comparative ecology of Galapagos ground finches (Geospiza Gould): Evaluation of the importance of floristic diversity and interspecific competition. Ecol. Monogr., 47: 151-184.

Amadon, D., 1962. Family Sturnidae, starlings. In: E. Mayr \& J. C. Greenway eds., Checklist of birds of the world, 15: 75-121 (Museum of Comparative Zoology, Cambridge, Mass.).

AlI, S. \& S. D. RIPLeY, 1972. Handbook of the birds of India and Pakistan, 5: i-xiii, 1-276, pls. 55-64 (Oxford Univ. Press, Bombay).

AtchleY, W. R., 1971. A comparative study of the cause and significance of morphological variation in adults and pupae of Culicoides: a factor analysis and multiple regression study. Evolution, 25: 563-583.

Austin, O. L., 1962. Birds of the world: 1-3.16, pls. (Golden Press, New York)

BAKER, A. J., 1980. Morphometric differentiation in New Zealand populations of the House Sparrow (Passer domesticus). Evolution, 34: 638-653.

BAKER, A. J. \& A. MOEED, 1979. Evolution in the introduced New Zealand populations of the Common Myna, Acridotheres tristis (Aves: Sturnidae). Can. J. Zool., 57: 570-584.

Baker, A. J., R. L. Peterson, J. L. Eger \& T. H. Manning, 1978. Statistical analysis of geographic variation in the skull of the Arctic Hare (Lepus arcticus). Can. J. Zool., 56: 2067-2082.

Benson, C. W., 1960. The birds of the Comoro Islands. Ibis, 103: 5-106.

Brooke, R. K., 1976. Morphological notes on Acridotheres tristis in Natal. Bull. Br. Orn. Club, 96: 8-13.

Bryant, E. H., 1977. Morphometric adaptation of the Housefly, Musca domestica L., in the United States. Evolution, 31: $580-596$.

Cody, M. L., 1973. Character convergence. Ann. Rev. Ecol. Syst., 4: 189-211.

CoOley, W. W. \& P. R. Lohnes, 1971. Multivariate data analysis: i-x, 1.364 (Wiley, New York).

Derrick, R., 1965. The Fijian Islands; a geographical hand. book: 1-334 (Government Press, Suva).

Dunmire, W. W., 1961. Birds of the National Parks in Hawaii: 1-36, pl. 1 (Hawaii Natural History Society, Honolulu).

GABRIEL, K. R. \& R. R. SOKAI, 1969. A new statistical approach to geographic variation analysis. Syst. Zool., 18: 259-278.

Gibson, A. R., M. A. Gates \& R. ZACH, 1976. Phenetic affinities of the Wood Thrush, Hylocichla mustelina (Aves: Turdinae). Can. J. Zool., 54: 1679-1687.

Hall, R., 1907. The useful birds of southern Australia: 1306 (Lothian, Melbourne).

Hamilton, T. H., 1958. Adaptive variation in the genus Vireo. Wilson Bull., 70: 307-346,
1961. The adaptive significances of intraspecific trends of variation in wing length and body size among bird species. Evolution, 15: 180-195.

HARMAN, H. H., 1967. Modern factor analysis: i-xx, 1-474 (University of Chicago Press, Chicago).

Hespenheide, H. A., 1966. The selection of seed size by finches. Wilson Bull., 78: 191-197.

- 1973 . Ecological inferences from morphological data. Ann. Rev. Ecol. Syst., 4: 213-229.

JAMES, F. C., 1970. Geographic size variation in birds and its relationship to climate. Ecology, 51: $365-390$.

Johnston, R. F. \& R. K. Selander, 1971. Evolution in the House Sparrow, 2. Adaptive differentiation in North American populations. Evolution, 25: 1-28.

- \& - 1973. Evolution in the House Sparrow, 3. Variation in size and sexual dimorphism in Europe and North and South America. Amer. Natural., 107: 373-390.

Jolicoeur, P. \& J. E. MosimanN, 1960. Size and shape variation in the Painted Turtle. A principal components analysis. Growth, 24: 339-354.

KAISER, H. F., 1958. The varimax criterion for analytical rotation in factor analysis. Psychometrika, 23: 187-200.

KeNT, C. C., 1927. The Indian Myna. S. Afr. Journ. nat. Hist., 6: 127-129.

Kluge, A. G. \& W. C. Kerfoot, 1973. The predictability and regularity of character divergence. Amer. Natural., 107: 426-442.

MACArthur, R. H., 1958. Population ecology of some warblers in northeastern coniferous forests. Ecology, 39: 599-619.

- 1972. Geographical ecology; patterns in the distribution of species: i-xviii, 1.269 (Harper \& Row, New York).

MCNAB, B. K., 1971. On the ecological significance of Bergmann's Rule. Ecology, 52: 845-854.

MOREAU, R. E., 1957. Variation in the western Zosteropidae (Aves). Bull. Brit. Mus. (nat. Hist.) Zool., 4: 311-433.

Mosimann, J. E. \& F. C. JAmes, 1979. New statistical methods for allometry with application to Florida Redwinged Blackbirds. Evolution, 33: 444-459.

POWER, D. M., 1969. Evolutionary implications of wing and size variation in the Red-winged Blackbird in relation to geographic and climatic factors: a multiple regression analysis. Syst. Zool., 18: 363-373.

—, 1970. Geographic variation in Red-winged Blackbirds in central North America. Univ. Kansas Publ. Mus. nat. Hist., 19: 1-83.

Pulliam, H. R. \& F. Enders, 1971. The feeding ecology of five sympatric finch species. Ecology, 52: $557-566$.

Rosenzweig, M. L., 1968. The strategy of body size in mammalian carnivores. Amer. Midland Natural., 80: 299-315.

SCHOENER, T. W., 1965. The evolution of bill size differences among sympatric congeneric species of birds. Evolution, 19: 189-213.

- 1970 . Size patterns in West Indian Anolis lizards, 2. Correlations with size of particular sympatric species displacement and convergence. Amer. Natural., 104: 155-174.

SEAL, H. L., 1906. Multivariate statistical analysis for biologists: i-ix, 1-207 (Methuen, London).

Sengupta, S., 1976. Food and feeding ecology of the Common Myna, Acridotheres tristis (Linn.). Proc. Indian natn. Sci. Acad., 42B: 338-345.

Sokal, R. R., 1976. The Kluge-Kerfoot phenomenon re- 
examined. Amer. Natural., 110: 1077-1091.

- 1978. Population differentiation - something new or more of the same? In: P. F. BRussard ed., Ecological genetics: The interface: 215-239 (Springer-Verlag, New York).

SNow, D. W., 1954. Trends in geographical variation in the Palearctic members of the genus Parus. Evolution, 8: 19-28.

Thomson, G. M., 1922. The naturalisation of animals and plants in New Zealand: i-viii, 1-607 (Cambridge University Press, London).
Watling, R. J., 1975. Observations on the ecological sepasation of two introduced congeneric mynahs (Acridotheres) in Fiji. Notornis, 22: 37-53.

Willson, M. F., 1971. Seed selection in some North American finches. Condor, 73: 415-429.

Willson, M. F. \& J. C. Harmeson, 1973. Seed preferences and digestive efficiency of cardinals and song sparrows. Condor, 75: 225-234.

Woods, A., 1974. Pest control: a survey: 1-407 (McGrawHill, New York).

Received: 16 June 1980 